Revista Brasileira de

Engenharia Agrícola e Ambiental

v.14, n.11, p.1234-1239, 2010

Campina Grande, PB, UAEA/UFCG - http://www.agriambi.com.br

agriambi

Protocolo 010.10 - 01/02/2010 • Aprovado em 02/08/2010

\title{
Comprimento das estacas e parte do ramo para formação de mudas de pinhão-manso
}

\author{
Rosiane L. S. de Lima ${ }^{1}$, Liv S. Severino ${ }^{2}$, Walter E. Pereira ${ }^{3}$, \\ Amanda M. A. de Lucena ${ }^{4}$, Hans R. Gheyi ${ }^{5} \&$ Nair H. C. Arriel ${ }^{2}$
}

RESUMO

Tradicionalmente, a propagação do pinhão-manso (Jatropha curcas) é realizada através de sementes; e em muitas situações a propagação vegetativa é uma importante alternativa para a propagação desta espécie. O bjetivou-se, com este trabalho, avaliar como o comprimento e a parte do ramo de onde se extraem as estacas influenciam a capacidade de enraizamento adventício e de crescimento de mudas de pinhão-manso. 0 s tratamentos foram arranjados em esquema fatorial $3 \times 4$, sendo os fatores três posições da estaca no ramo (apical, mediana e basal) e quatro comprimentos de estaca (10, 15, 20 e $25 \mathrm{~cm}$ ). Adotou-se 0 delineamento inteiramente casualizado com quatro repetições e dez estacas por parcela. Aos 70 dias após o estaqueamento foi avaliado o número de brotações e de ramos formados, o comprimento dos ramos, número de folhas, área foliar, número de raízes, massa seca de brotações e massa seca de raízes, cujos resultados indicaram que a posição do ramo em que se extrai a estaca de pinhão-manso (base, meio ou ápice) não influencia o crescimento inicial ou a formação das mudas; no entanto, o comprimento da estaca modifica o crescimento inicial das mudas sendo que o maior crescimento é obtido com estacas em torno de $22 \mathrm{~cm}$.

Palavras-chave: Jatropha curcas, estaquia, propagação vegetativa

\section{Length of cuttings and the part of the branch section for production of Jatropha seedlings}

\begin{abstract}
Jatropha curcas is traditionally propagated by seed. However, in several situations the vegetative propagation is an importantalternative and its technology needs to be developed. The objective of this study was to evaluate how the length and the portion of the branch from where the cuttings are extracted, influence the rooting and growth capacity of Jatropha cuttings. The treatments were arranged in a $3 \mathrm{x}$ 4 factorial design, with three cutting positions (apical, middle and basal) and four cutting lengths $(10,15,20$, and $25 \mathrm{~cm})$. A completely randomized design with four replications and ten cuttings per plot was adopted. At 70 days after planting, the cuttings were evaluated for the number of sprouts and branches, branch length, number of leaves, leaf area, number of roots, and dry mass of shoots and roots. The position from where the cuttings are extracted (apical, middle or basal) did not influence its capacity for rooting and the growth of the seedlings. The cutting length influences the initial growth, and the best growth was obtained in cuttings of around $22 \mathrm{~cm}$.
\end{abstract}

Key words: Jatropha curcas, cuttings, vegetative propagation

\footnotetext{
1 Pesquisadora DCR pela FAPESQ/PB/CN Pq. Rua Treze de Maio, 21, AP-202, Centro, CEP 58400-290, Campina Grande, PB. Fone: (83) 9168-2037. E-mail: limarosiane@yahoo.com.br

2 Pesquisador da Embrapa Algodão. Rua 0 svaldo Cruz 1126, Centenário, CEP 58428-035, Campina Grande, PB. E-mail: liv@cnpa.embrapa.br; nair@cnpa.embrapa.br; vsofiatti@cnpa.embrapa.br

3 DCFS/UFPB, CEP 58397-000, Areia, PB. Fone: (83) 3362-2300. E-mail: wep@cca.ufpb.br

${ }^{4}$ Bolsista do CN Pq/Embrapa Algodão, Rua 0 svaldo Cruz 1126, Centenário, CEP 58107-720, Campina Grande, PB. Fone: (83) 3182-4353. E-mail: amandamicheline@hotmail.com

${ }^{5}$ NEAS/U FRB, CEP 44380-000, Cruz das Almas, BA. Fone: (83) 3310-1056. E-mail: hans@deag.ufcg.edu.br
} 


\section{INTRODUÇÃO}

O pinhão-manso é uma espécie perene cuja produção de mudas por estaquia é facilitada devido à sua facilidade para enraizar (Kathiravan et al., 2009). De acordo com Peixoto (1973) e Arruda et al. (2004), estacas colhidas de ramos lenhosos com até 2 anos de idade e localizadas na base dos ramos, são as mais indicadas para o enraizamento.

São inúmeras as vantagens oferecidas pela propagação por estaquia, dentre as quais se destacam a precocidade da planta em atingir o estádio produtivo e a padronização das características agronômicas das plantas matrizes previamente selecionadas (Kathiravan et al., 2009). Dentre as desvantagens para a cultura do pinhão-manso, Cortesão (1956) destaca a diminuição no ciclo da cultura e a fragilidade do sistema radicular adventício e Saturnino et al. (2005) acrescentam que para propagar o pinhão-manso por estaquia em escala comercial é preciso grande volume de material propagativo.

Algumas pesquisas relacionadas com o enraizamento de estacas de pinhão-manso foram publicadas recentemente, a exemplo das realizadas por Jepsen et al. (2006), Kochhar et al. (2008), Noor Camellia et al. (2009) e Shivastava \& Banerijee. (2009). Porém aspectos como o tamanho e a posição de colheita da estaca no ramo ainda não foram totalmente definidos, restringindo-se aos resultados obtidos por Feike et al. (2007) e Kathiravan et al. (2009), os quais constataram que estacas colhidas da posição basal do ramo e aquelas com 40 $\mathrm{cm}$ de comprimento e diâmetro variando entre 2,5 a 3,0 cm são mais adequadas para a propagação do pinhão-manso.

Vários fatores podem influenciar a formação de raízes adventícias em estacas, a exemplo do vigor da planta matriz, genótipo (Almeida et al., 2008 b), posição das estacas nos ramos utilizados (Lima et al., 2006; Garbuio et al., 2007), comprimento da estaca (Mayer et al., 2002), presença de folhas e gemas (Fochesato et al., 2006), grau de lignificação da estaca (Almeida et al., 2008 a; Noor Camellia et al., 2009), época do ano em que o material foi colhido (Pio et al., 2007), composição do substrato (Lima et al., 2007; Kumar et al., 2009), uso de reguladores de crescimento (Dhillon et al., 2009), idade do ramo (Jimu et al., 2009) e meio de cultivo (Heller, 1996; Singh et al., 2007), dentre outros.

Em geral, estacas caulinares colhidas da posição apical do ramo têm menor grau de lignificação, células meristemáticas com metabolismo mais ativo e ausência ou menor quantidade de compostos fenólicos, o que facilita o enraizamento e o brotamento (Hartmann et al., 2004). Porém, baixos índices de pegamento podem ocorrer devido à maior predisposição dessas estacas tenras em perderem umidade (Lima et al., 2006). De acordo com Gondim et al. (2001), a posição da estaca no ramo e o tamanho a ser usado precisam ser bem definidos quando se deseja propagar uma espécie por estaquia, pois a escolha inadequada das estacas pode resultar em elevadas taxas de mortalidade e inviabilizar o processo de propagação.

Outro fator que influencia a capacidade de enraizamento das estacas é o teor de carboidratos visto que, ao longo do ramo, seu teor, tal como a quantidade de substâncias inibidoras ou promotoras do enraizamento, apresenta variações, constituindo, assim, um dos motivos pelos quais as estacas colhidas de diferentes porções do ramo tendem a diferir quanto ao potencial de enraizamento (Hartmann et al., 2004).

Objetiva-se com este experimento avaliar a importância do comprimento e da posição da estaca no ramo para o enraizamento de mudas de pinhão-manso.

\section{MATERIAL E MÉTODOS}

Este experimento foi conduzido em casa de vegetação na Embrapa Algodão (Latitude - $07^{\circ} 13^{\prime} 50^{\prime \prime}$, Longitude $35^{\circ} 52^{\prime}$ 52'), situada na cidade de Campina Grande, PB, no período de março a maio de 2009. Para o estudo foram colhidas estacas com quatro tamanhos e três posições de ramos semilenhosos, obtidas de plantas-matrizes originadas no município de Itatuba, PB. As plantas faziam parte de uma pequena coleção de indivíduos, originados de sementes, obtidas na região e se encontravam com 1,5 ano de idade.

Os ramos foram colhidos nas primeiras horas da manhã e segmentados em estacas das porções apical, mediana e basal, com 10, 15, 20 e $25 \mathrm{~cm}$ de comprimento. As estacas utilizadas no ensaio apresentavam diâmetros caulinares variando entre 8,57 e 26,09 mm (Tabela 1).

Tabela 1. Diâmetro $(\mathrm{mm})$ da base de estacas caulinares de pinhão-manso colhidas da posição apical, mediana e basal, medindo 10, 15, 20 e $25 \mathrm{~cm}$ de comprimento

\begin{tabular}{lcccc}
\hline \multirow{2}{*}{$\begin{array}{c}\text { Posição da estaca } \\
\text { no ramo }\end{array}$} & \multicolumn{4}{c}{ Diâmetro $(\mathbf{m m})$} \\
\cline { 2 - 5 } & $\mathbf{1 0}$ & $\mathbf{1 5}$ & $\mathbf{2 0}$ & $\mathbf{2 5}$ \\
Apical & $8,57-13,04$ & $10,98-14,57$ & $13,75-14,89$ & $14,92-16,37$ \\
Mediana & $12,99-16,51$ & $13,46-17,54$ & $15,18-18,52$ & $16,84-19,44$ \\
Basal & $18,49-21,01$ & $18,61-22,36$ & $20,82-22,55$ & $21,96-26,09$ \\
\hline
\end{tabular}

Os cortes foram realizados na base das estacas, em forma de bisel, em um ângulo de aproximadamente $45^{\circ}$. Para tal procedimento, utilizou-se tesoura de poda. Após a segmentação dos ramos e obtenção das estacas em seus devidos comprimentos, foram acondicionadas em sacos plásticos e armazenadas em caixas térmicas, contendo água, objetivando-se manter as estacas hidratadas.

As estacas, classificadas conforme a posição de coleta no ramo e o comprimento, foram plantadas $24 \mathrm{~h}$ após a coleta em vasos de polietileno, perfurados na base, com capacidade para $3 \mathrm{dm}^{3}$, contendo a mistura de terra e esterco bovino na proporção volumétrica de 2:1, respectivamente. As estacas foram plantadas a $5 \mathrm{~cm}$ de profundidade no sentido base ápice. Os 12 tratamentos foram constituídos pela combinação de três posições de coleta das estacas nos ramos e quatro comprimentos de estacas, arranjados no esquema fatorial $3 \times 4$, com quatro repetições, em delineamento inteiramente casualizado. Cada unidade experimental foi constituída por 10 estacas.

As mudas foram irrigadas diariamente com água de abastecimento (apresentando CE de $0,5 \mathrm{dS} \mathrm{m}^{-1}$, e íons sódio e cloreto predominantes), e mantidas livres da competição de plantas daninhas. Não houve qualquer ataque de pragas ou 
doenças que exigissem controle químico; aos 70 dias após o plantio (DAP) foi avaliada a percentagem de enraizamento (\%), o número de brotações, o número de ramos, o número de folhas, a área foliar, a massa seca de brotações e massa seca de raízes. As estacas não foram incluídas na medição da massa seca da parte aérea ou raízes. A área foliar foi estimada pela equação Área $=\mathrm{L}^{1,87}$ sugerida por Severino et al. (2007), na qual $\mathrm{L}=$ largura da folha. Para a obtenção da massa seca $\mathrm{o}$ material vegetal foi secado em estufa de circulação de ar a 70 ${ }^{\circ} \mathrm{C}$ até peso constante.

Os dados foram submetidos à análise de variância e regressão polinomial para se determinar o comprimento das estacas mais adequado. Para comparação entre as posições das estacas nos ramos, foi aplicado o teste de Tukey a 0,05 de probabilidade, segundo recomendações de Santos \& Gheyi (2003).

\section{RESULTADOS E DISCUSSÃO}

A posição da estaca no ramo não afetou as características de crescimento, constatando-se efeitos isolados apenas do fator comprimento das estacas (Tabela 2).

Tabela 2. Resumo da análise de variância e regressão polinomial para as variáveis percentagem de enraizamento (PER), número de brotos (NB), número de ramos (NR), número de folhas (NF), área foliar (AF), massa seca da parte aérea (MSPA), massa seca do sistema radicular (MSR)

\begin{tabular}{|c|c|c|c|c|c|c|c|c|}
\hline \multirow{2}{*}{ F.V. } & \multirow{2}{*}{ GL } & \multicolumn{7}{|c|}{ Quadrados médios } \\
\hline & & PER & NB & NR & NF & AF & MSPA & MSR \\
\hline $\begin{array}{l}\text { Posição } \\
\text { (P) }\end{array}$ & 2 & 277,7 & 0,50 & 0,30 & 6,38 & 108,30 & 1,5 & 0,005 \\
\hline $\begin{array}{l}\text { Comp. } \\
\text { (C) }\end{array}$ & 3 & $6203^{*}$ & $0,69 *$ & $0,51 *$ & $12,7^{*}$ & $513,66 *$ & $2,83^{*}$ & $0,027 *$ \\
\hline$C X P$ & 6 & 648,1 & 0,34 & 0,11 & 1,09 & 37,60 & 0,53 & 0,005 \\
\hline Resíduo & 24 & 1388,0 & 0,22 & 0,11 & 2,55 & 83,02 & 0,64 & 0,006 \\
\hline CV (\%) & - & 46,2 & 25,4 & 21,1 & 37,4 & 45,6 & 33,5 & 7,03 \\
\hline \multicolumn{9}{|c|}{ Regressão (C) } \\
\hline Linear & 1 & $16055^{*}$ & $1,37 *$ & $0,94 *$ & $30,5^{*}$ & $1177 *$ & $9,7^{*}$ & $0,08 *$ \\
\hline $\begin{array}{l}\text { Quadrát- } \\
\text { ico }\end{array}$ & 1 & 2500 & 0,02 & $0,53^{*}$ & $7,19 *$ & $360 *$ & $3,6 *$ & 0,0001 \\
\hline Desvio & 1 & 55 & 0,68 & 0,06 & 0,44 & 2,9 & 0,02 & 0,001 \\
\hline
\end{tabular}

* significativo a $5 \%$ de probabilidade pelo teste $\mathrm{F}$

A influência do comprimento da estaca no enraizamento e no desenvolvimento da muda pode ser muito variável de acordo com a espécie e as condições do meio de cultivo. Segundo Heller (1996), fatores como composição do substrato, aeração e drenagem influenciam significativamente o índice de sobrevivência e desenvolvimento de mudas propagadas por estaquia. Um dos fatores que afetam a sobrevivência das estacas na produção de mudas de pinhão-manso é o diâmetro da estaca. Neste sentido, Jimu et al. (2009) constataram que o uso de estacas de pinhão-manso com $5 \mathrm{~cm}$ de espessura e $25 \mathrm{~cm}$ de comprimento não apresentou resultados favoráveis quanto à sobrevivência e ao desenvolvimento das mudas, atribuindo-se-lhes às condições desfavoráveis do ambiente de cultivo.

A percentagem de enraizamento foi influenciada pelo comprimento da estaca, constatando-se efeito linear para esta variável (Figura 1A). Estacas com $10 \mathrm{~cm}$ de comprimento apresentaram a menor percentagem de enraizamento quando comparada aos demais comprimentos estudados. Para Thitithanavanich (1985), estacas de pinhão-manso com $3 \mathrm{~cm}$ de diâmetro e $30 \mathrm{~cm}$ de comprimento apresentam maior índice de

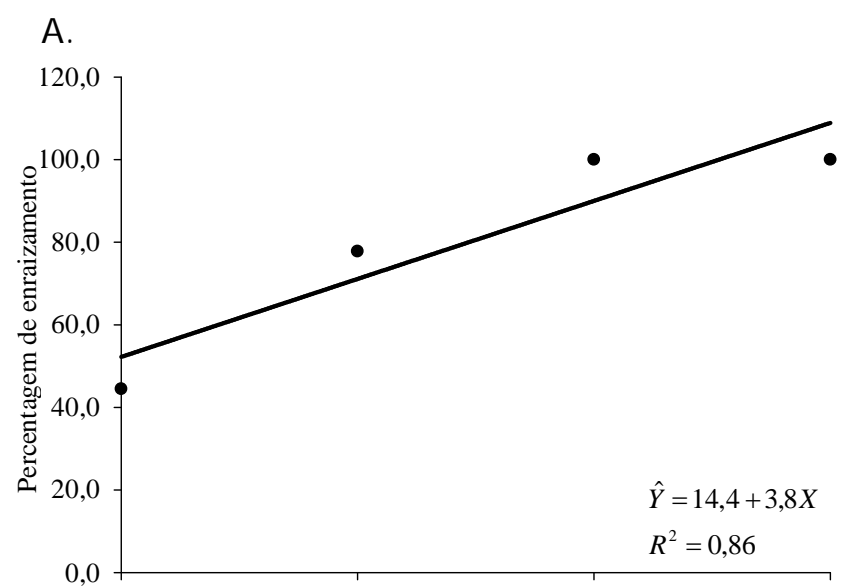

B.
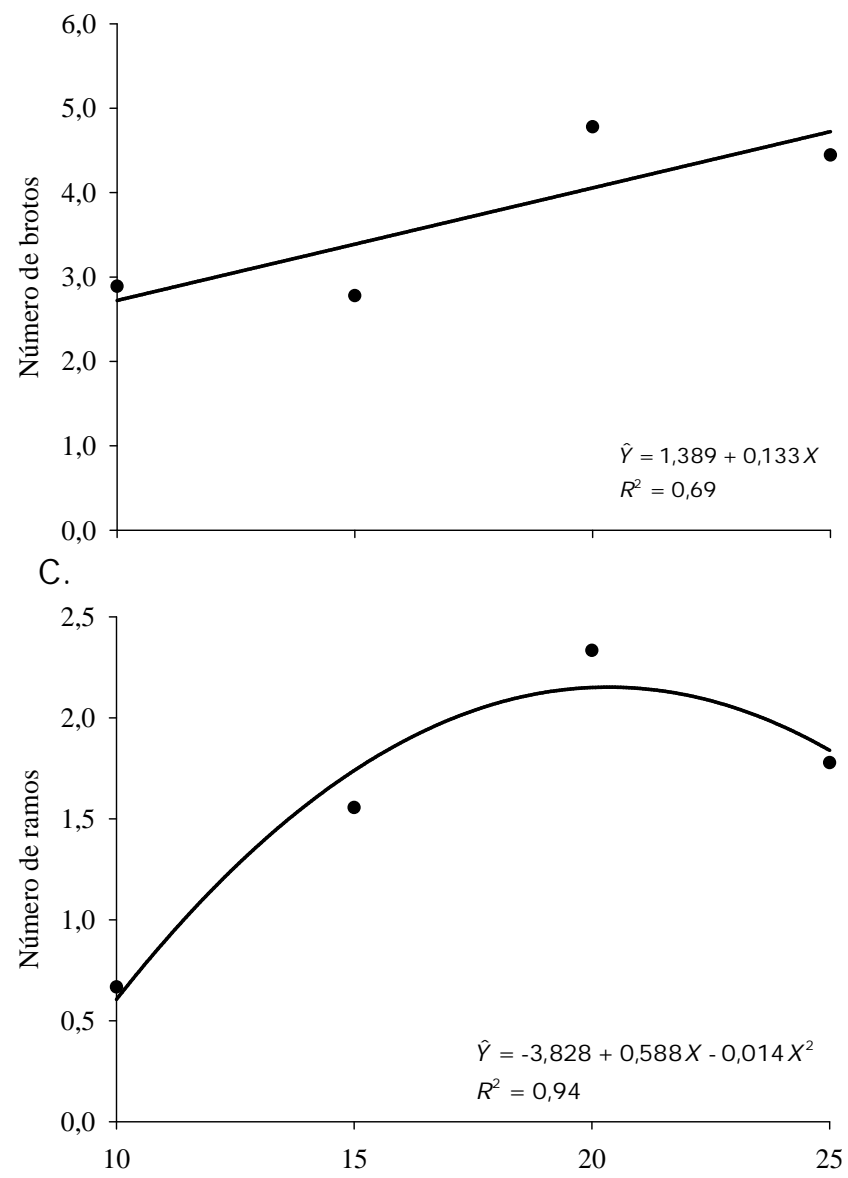

Comprimento das estacas $(\mathrm{cm})$

Figura 1. Efeito do comprimento das estacas sobre a percentagem de enraizamento (A), número de brotos (B) e número de ramos (C) de mudas de pinhão-manso propagadas por estaquia 
sobrevivência e enraízam melhor do que aquelas com 1 a 2 $\mathrm{cm}$ de diâmetro e $15 \mathrm{~cm}$ de comprimento. Em verticillata (Cissus sicyoides), estacas com 10 e $20 \mathrm{~cm}$ de comprimento não apresentaram diferenças em relação ao número e comprimento das raízes (Abreu et al., 2003), e a variação no comprimento das estacas de fáfia (Pfaffia glomerata) também não afetou a porcentagem de enraizamento, nem a produção de massa seca de folhas e raízes (Nicoloso et al., 2001). Por outro lado, para a produção de mudas de cidreira (Lippia alba) (Mota \& Araújo, 2009) e alecrim-pimenta (Lippia sidoides) (Carvalho Júnior et al., 2009) o comprimento da estaca afetou significativamente o enraizamento, em especial a produção de massa seca das raízes. O potencial de enraizamento de estacas caulinares pode ser influenciado pela idade da planta matriz e pela posição da estaca no ramo (Hartmann et al., 2004) e é dependente da espécie vegetal (Nicoloso et al., 2001). Assim, é possível que o menor índice de sobrevivência das estacas, observado neste estudo, esteja relacionado ao fato das estacas terem sido colhidas de ramos com apenas 1,5 ano (Heller, 1996) e apresentarem menor grau de lignificação e reserva de carboidratos (Noor Camellia et al., 2009).

Independentemente da posição da estaca no ramo, o brotamento ocorreu aos 12 dias após o plantio, observando-se a morte de algumas estacas com $10 \mathrm{~cm}$ de comprimento. O número de brotações aumentou linearmente de acordo com o incremento no comprimento das estacas, notando-se 3 brotos nas estacas com $10 \mathrm{~cm}$ e 5 brotos nas de $25 \mathrm{~cm}$ (Figura 1B).

Embora o número de brotações tenha aumentado linearmente com o aumento do comprimento do ramo, o número de ramos que se desenvolveram a partir dessas brotações aumentou de forma quadrática (Figura 1C) e atingiu um valor máximo quando as estacas apresentavam comprimento estimado de 20,7 cm. Segundo Paiva et al. (1999), usar estacas curtas é uma opção quando há necessidade de propagar genótipos superiores, cuja disponibilidade de plantas-matrizes é limitada; e, entretanto, estacas longas podem tornar-se mais suscetíveis à desidratação devido à grande superfície exposta ao ambiente e à maior demanda de água para suprir a grande quantidade de tecido, além de aumentar consideravelmente o volume de material propagativo a ser transportado e manuseado. Esses prós e contras justificam a necessidade de otimização do comprimento das estacas para produção de mudas de pinhão-manso.

O número de folhas, a área foliar e a massa seca da parte aérea, apresentaram aumento com o incremento do tamanho das estacas, até o comprimento estimado de 22,1, 20,9 e 23 $\mathrm{cm}$ (Figura $2 \mathrm{~A}, \mathrm{~B}$ e C), respectivamente. Essas características estão associadas ao número de ramos e por isso se comportaram de maneira similar. Assim, se considerando as várias características de crescimento estudadas, tem-se que o maior crescimento das plantas foi estimado em estacas de comprimento em torno de $22 \mathrm{~cm}$.

A massa seca do sistema radicular das plantas (Figura 2D), que corresponde à emissão de raízes adventícias, se relacionou, linearmente, com o comprimento das estacas, de forma similar à variável percentagem de enraizamento. Lima et al.
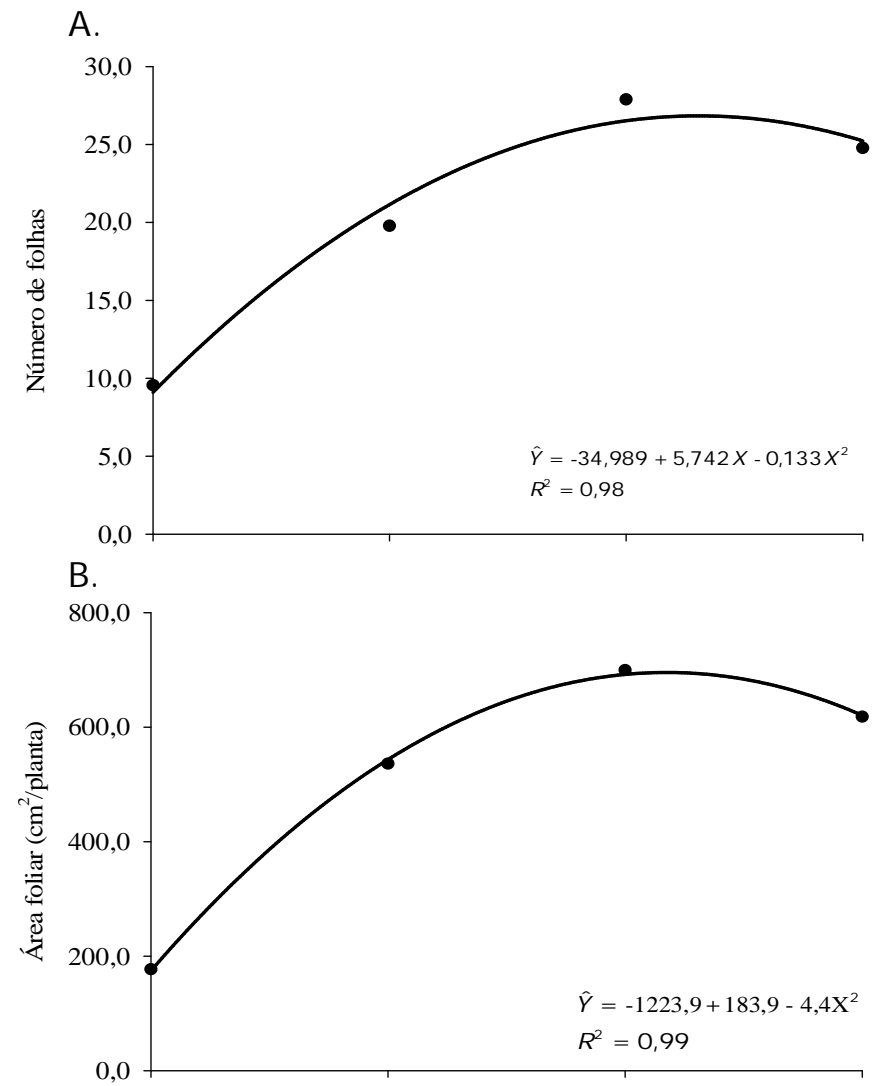

C.

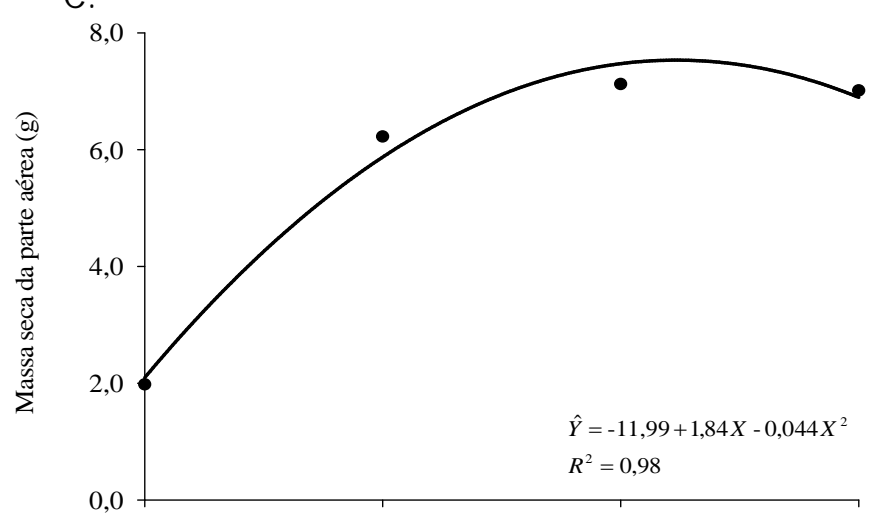

D.

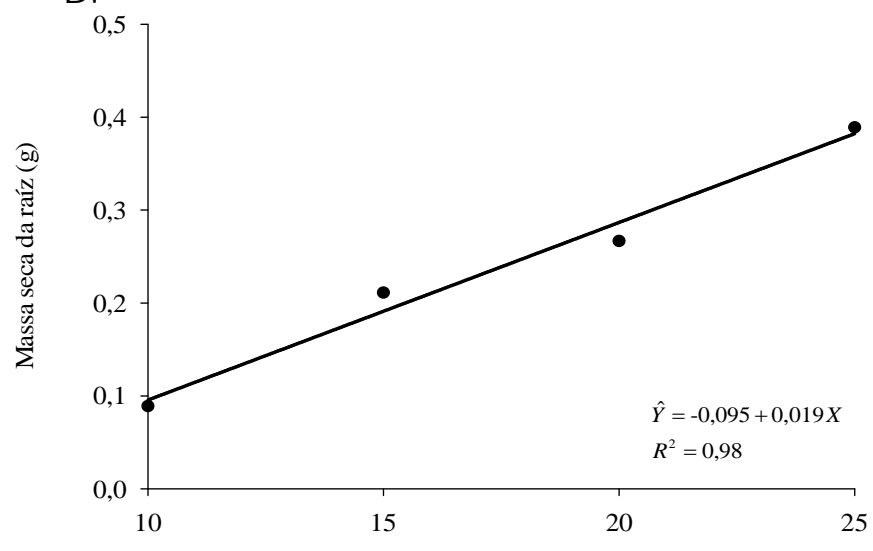

Comprimento das estacas $(\mathrm{cm})$

Figura 2. Efeito do comprimento das estacas sobre o número de folhas $(A)$, área foliar (B), massa seca de parte aérea (C) e massa seca de raízes (D), de mudas de pinhão-manso propagadas por estaquia 
(2006) afirmam que a quantidade de raízes é um fator importante para o vigor das mudas. A massa seca de raízes produzida não foi influenciada pela posição da estaca no ramo, observando-se efeitos significativos apenas para o comprimento dos ramos.

Este estudo considerou apenas o crescimento inicial das mudas, porém para que se otimizem o comprimento e a posição da estaca é preciso, ainda, serem feitas avaliações dessas mudas após o transplante e adaptação ao ambiente. Possivelmente, as plantas com maior massa de raízes e área foliar estarão em vantagem ao serem transplantadas, mas outros fatores podem, também, influenciar seu desempenho, tais como, a formação da copa, os usos das reservas da estaca para sustentar o crescimento inicial e as características das raízes produzidas, além de outros.

\section{CONCLUSÕES}

1. A posição de corte da estaca na planta de pinhão-manso (base, meio ou ápice) não influencia o crescimento inicial das mudas.

2. O comprimento da estaca influencia o crescimento inicial das mudas, sendo o maior crescimento obtido com estacas em torno de $22 \mathrm{~cm}$.

\section{AGRADECIMENTOS}

Ao Convênio FAPESQ/PB/CNPq, pelo apoio financeiro.

\section{LITERATURA CITADA}

Abreu, I. N.; Pinto, J. E. B. P.; Bertolucci, S. K. V.; Morais, A. R. de.; Geromel, C.; Laderira, A; Lameira, O. A. Propagação in vivo e in vitro de Cissus sicyoides, uma planta medicinal. Acta Amazônica, v.33, n.1, p.1-7, 2003.

Almeida, E.; Esus, N. de.; Scalopii, E. M. T.; Martins, J. A. B. G.; Araújo, M. S. Propagação de três genótipos de abieiro (Pouteria caimito) por estaquia de ramos herbáceos. Acta Amazônica, v.38, n.1, p.1-4, 2008a.

Almeida, E.; Scalopii, E. M. T.; Jesus, N.; Martins, A. B. G. Propagação de jambeiro Vermelho (Syzygium malaccense L.) por estaquia de ramos herbáceos. Bioscience Journal, v.24, n.1, p. $39-45,2008 b$.

Arruda, F. P. de; Beltrão, N. E. de M.; Andrade, A. P. de.; Pereira, W. E.; Severino, L. S. Cultivo de pinhão manso (Jatropha curcas L.) como alternativa para o semi-árido nordestino. Revista Brasileira de Oleaginosas e Fibrosas, v.8, n.1, p.789-799, 2004.

Carvalho Júnior, W. G. O.; Melo, M. T. P. de.; Martins, E. R. Comprimento da estaca no desenvolvimento de mudas de alecrim-pimenta. Ciência Rural, v.39, n.7, p.2199-2202, 2009.

Cortesão, M. Culturas tropicais: Plantas oleaginosas. Lisboa: Clássica, 1956. 231p.
Dhillon, R. S.; Hooda, M.S.; Pundeer, J. S.; Ahlawat, R. S.; Kumari, S. Development of efficient techniques for clonal multiplication of Jatropha curcas L., a potential biodiesel plant. Current Science, v.96, n.6,p.823-827 2009.

Feike, T.; Weis, K.; Claupein, W.; Mueller, J. Propagation of physic nut (Jatropha curcas L.) on Leyte Island, Philippines. In: Conference on International Agricultural Research for Development. Proceedings... Witzenhausen: University of Kassel/ University of Göttingen, 2007. p.1-6.

Fochesato, M. L.; Martins, F. T.; Souza, P. V. D.; Schwarz, S. F.; Barros, I. B. I. Propagação de louro (Laurus nobilis L.) por estacas semilenhosas com diferentes quantidades de folhas e tratadas com ácido indolbutírico. Revista Brasileira de Plantas Medicinais, v.8, n.3, p.72-77, 2006.

Garbuio, C.; Biasi, L. A.; Kowalski, A. P. J. Propagação por estaquia em Patchouli com diferentes números de folhas e tipos de estacas. Scientia Agrária, v.8, n.4, p.435-438, 2007.

Gondim, T. M. de S.; Ledo, F. J. da. S.; Cavalcante, M. de J. B.; Souza, A. das G. C. Efeito da porção do ramo e comprimento de estacas na propagação vegetativa de plantas de cupuaçu. Revista Brasileira de Fruticultura, v.23, n.1, p.203-205, 2001.

Hartmann, H. T.; Kester, D. E.; Davies, F. T.; Geneve, R. L. Plant propagation: Principles and practices. 7.ed. New Jersey: Prentice Hall, 2004. 880p.

Heller, J. Physic nut Jatropha curcas L. Promoting the conservation and use of underutilized and neglected crops. 1. Rome: Institute of Plant Genetic Resources and Crop Plant Research: Gatersleben/International Plant Genetic Resources Institute: 1996.66 p.

Jepsen, J. K.; Henning, R. K.; Nyati, B. Generative propagation of Jatropha curcas L. on Kalahari Sand. Environment África, 2006. http://www.jatropha.de/.../The $\% 20$ generative $\% 20$ propagation\%20of\%20JCL.pdf. 31 Jan. 1010.

Jimu, L.; Nyakudya, I. W.; Katsvanga, C. A. T. Establishment and early field performance of Jatropha curcas L. at Bindura University Farm, Zimbabwe. Journal of Sustainable Development in Africa, v.10, n.4, p.45-469, 2009.

Kathiravan, A. S.; Ponnuswamy, A. S.; Vanitha, C. Determination of suitable cutting size for vegetative propagation and comparison of propagules to evaluate the seed quality attributes in Jatropha curcas Linm. Natural Product Radiance, v.8, n.2, p.162-166, 2009.

Kochhar, S.; Sing, S. P.; Kochar, V. P. Effect of auxins and associated biochemical changes during clonal propagation of the biofuel plant - Jatropha curcas. Biomass and Bioenergy, v.32, n.12, p.1136-1143, 2008.

Kumar, A.; Sharma, S.; Mishra, S. Aplication of farmyard manure and vermicompost on vegetative and generative characteristics of Jatropha curcas. Journal of Phytology, v.1, n.4, p.206-212, 2009.

Lima, R. L. S.; Siqueira, D. L.; Weber, O. B.; Cazetta, J. O. Comprimento de estacas e parte do ramo na formação de mudas de aceroleira. Revista Brasileira de Fruticultura, v.28, n.1, p.83-86, 2006.

Lima, Y. O. U.; Ritter, M.; Alcântara, G. B.; Lima, O. M.; Fogaça, L. A.; Quoirin, M.; Cuquel, F. L.; Biasi, L. A. Tipos de estacas e substratos no enraizamento do jambolão. Scientia Agrária, v.8, n.4, p.449-453, 2007. 
Mayer, N. A.; Pereira, F. M.; Nachtigal, J. C. Efeito do comprimento de estacas herbáceas de dois clones de umezeiro (Prunus muma Sieb \& Zucc.) no enraizamento adventício. Revista Brasileira de Fruticultura, v.24, n.2, p.500-504, 2002.

Mota, J. H.; Araújo, C. de. Avaliação do tamanho de estacas no enraizamento de erva-doce. Horticultura Brasileira, v.27, n.2, p.30-33, 2009.

Nicoloso, F. T.; Cassol, L. F.; Fortunato, R. P. Comprimento da estaca de ramo no enraizamento de gingseng brasileiro ( $P f a-$ ffia glomerata). Ciência Rural, v.31, n.1, p.5-60, 2001.

Noor Camellia, N. A.; Thohirah, L. A.; Abdullah, N. A. P.; Mohd Khidir, O. Improvement on rooting quality of Jatropha curcas using indole butyrico acid (IAB). Research Journal of Agriculture and Biological Sciences, v.5, n.4, p.338-343, 2009.

Paiva, J. R.; Paiva, W. O.; Cordeiro, E. R.; Sabry Neto, H. Parâmetros genéticos em progênies de polinização livre de acerola. Pesquisa Agropecuária Brasileira, v.34, n.4, p.629-634, 1999.

Peixoto, A. R. Plantas oleaginosas arbóreas. São Paulo: Nobel, 1973. 284p.

Pio, R.; Dall 'orto, F. A. C.; Alvarenga, A. A.; Abrahão, E.; Chagas, E. A.; Signorini, G. Propagação de marmeleiro 'Japonês' por estaquia e alporquia realizadas em diferentes épocas. $\mathrm{Ci}$ ência e Agrotecnologia, v.31, n.2, p.570-574, 2007.
Santos, J. W. dos; Gheyi, H. R. Estatística experimental aplicada. Campina Grande: Editora Gráfica Marcone, 2003. 213p.

Saturnino, H. M.; Pacheco, D. D.; Kakina, J.; Tominaga, N.; Gonçalves, N. P. Cultura do pinhão manso (Jatropha curcas L.). Revista Informe Agropecuário, n.229, p.44-78, 2005.

Severino, L. S.; Vale, L. S.; Beltrão, N. E. M. A. simple method for measurement of Jatropha curcas leaf area. Revista Brasileira de Oleaginosas e Fibrosas, v.11, n.1, p.9-14, 2007.

Singh, R. N. A. A.; Munish, K.; Haider, E. Synergistic cropping of summer groundnut with Jatropha curcas. A new two-tier cropping system for Uttar Pradesh. ICRISAT Journal, v.5, n.1, p.1-2, 2007.

Shivastava, S.; Banerijee, M. In vitro clonal prpagation of physic nut (Jatropha curcas L.): Influence of additives. International Journal of Integrative Biology, v.3, n.1, p.73-79, 2009.

Thitithanavanich, B. The effect of diameter and length of stem-cuttings on root production of physic nut (Jatropha curcas L.) in Thailand. Bangkok Kasetsart University,1985. http://www.jsdafrica.com/.../Establishment\% 20 and $\% 20$ Early $\% 20$ Field $\% 20$ Performance.pd.31 jan.2010. 